\title{
KONTEKS HIJRAH NABI MUHAMMAD SAW DARI MEKKAH KE MADINAH MELALUI DAKWAH INDIVIDUAL KE PENGUATAN MASYARAKAT
}

\author{
Alfi Ahyuni \\ Sekolah Dasar Negeri Bangunrejo Kidul II Kedunggalar \\ alfiahyuni@gmail.com
}

\begin{abstract}
Abstrak
Setelah turun ayat 94, surah Al-Hijr, Nabi Muhammad Saw memulai berdakwah secara terang-terangan, namun dakwah yang dilakukan Nabi Muhammad Saw tidak mudah karena mendapat tantangan dari kaum kafir Quraisy. Perjanjian Aqobah menjadi dasar hijrah yang dilakukan Nabi Muhammad Saw dari Mekkah ke Yastrib (Madinah). Di Tengah komunitas baru tersebut, Nabi Muhammad Saw meletakkan dasar-dasar bermasyarakat yaitu: mendirikan masjid yang kemudian dikenal sebagai Masjid Nabawi, mempersatukan dan mempersaudarakan antara kaum Muhajirin dan kaum Anshor; ; membangun konsensus dan kesepakatan bersama antara umat Islam dengan kelompok agama lain yang ada di Yastrib; dan meletakkan dasar- dasar sosial, politik, ekonomi, budaya, dan keagamaan sebagai landasan membangun peradaban Islamiyah yang kemudian dikenal sebagai masyarakat madinah, yaitumasyarakat yang beradab.
\end{abstract}

Kata Kunci: Hijrah, Mekkah, Madinah, Dasar-dasar Kemasyarakatan

\section{PENDAHULUAN}

Selama 13 tahun hidup di Mekah, Rasulullah Saw serta para pengikutnya sering mengalami cobaan besar dan siksaan yang sangat pedih, disamping itu hak kemerdekaan mereka dirampas, mereka diusir dan harta benda mereka disita. Siksaan pedih berupa dera cambuk yang sangat meresahkan para sahabat dan kaum muslimin pada umumnya. Badan mereka dipanggang, kabel sejenis serabut diikiatkan pada tubuh karena tidak mau tunduk kepada selain Allah, Itulah tekanan yang sangat dasyat dialami Rasulullah beserta pengikutnya selama menyampaikan dakwah demi tersebarnya risalah tauhid di tengahtengah kaum kafir Quraisy. Denga sikap kaum Quraisy yang berkecamuk maka Rasulullah beserta kaum muslimin hijrah untukmenyelamatkan diri serta menyelamatkan agama tauhid, risalah kebenarannyayang sedang berada dalam tanggung jawabnya dengan tujuan untuk mencari tempat yang kondusif untuk selanjutnya menyusun kekuatan baru demi tercapainya kemenangan yang tertunda.

\section{PEMBAHASAN}

\section{Pengertian dan Faktor Pendorong Hijrah Nabi Muhammad Saw}

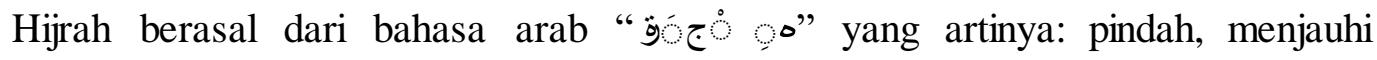

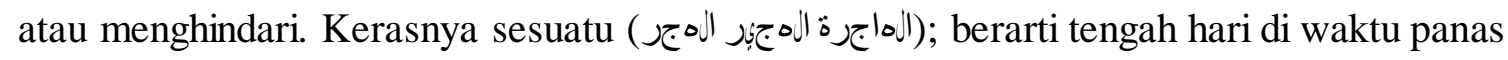
sangat menyengat (keras). Secara bahasa "hijrah" itu adalah Menjauhi sesuatu dengan sangat keras karena adanya ke tidak setujuaan dan kebencian. Hijrah adalah pindah, meninggalkan, menjauhi atau berpisah dari sesuatu dengan kebencian, menuju sesuatu yang dia sukai atau cintai, bukan pindah atau berpisah biasa biasa saja seperti pindah 
rumah. Dijauhinya sesuatu tersebut karena sesuatu tersebut mengandung Kekotoran / najis yang tidak disukainya. Meninggalkan pindah dari sesuatu tersebut bisa berarti secara fisik (pindah tempat) atau psikis.

Dalam sejarah perkembangan umat Islam, hijrah memiliki pengertian perpindahan Rasul bersama para sahabat ke Madinah, yang terjadi pada hari senin bulan Rabiul Awal pada tahun ketiga belas kenabian. Setelah terjadinya peristiwa Baiat Aqobah kedua, dan Islam memancangkan tonggak negara ditengah padang pasir yang bergelombang kekufuran dan kebodohan, dan ini merupakan hasil paling besar yang diperoleh Islam semenjak dakwah dimulai, maka Nabi Muhammad Saw dan orang-orang muslim di perkenankan untuk hijrah ke negara tersebut (Suhardi, 2012: 137).

Hijrahnya mereka bukan semata-mata untuk menjauhkan diri dari gangguan dan ejekan kaum Musyrikin Quraisy, tetapi sekaligus merupakan usaha bersama untuk mendirikan sebuah masyarakat baru di daerah yang aman. Rasulullah hijrah dari makah ke Madinah bukan tanpa alasan, ada beberapa latar belakang hijrah itu dilakukan oleh nabi. Prof. DR. Abu Su'ud dalam bukunya yang berjudul "Islamologi" menyebutkan tiga faktor yang melatar belakangi hijrah. Pertama, tawaran dan undangan kepada nabi untuk berhijrah ke Madinah, yang selanjutnya dapat dianggap sebagai pusat penyiaran Islam di Arab. Faktor ini bisa di analogikan sebagai faktor daya tarik (pull factor). Kedua, situasi keamanan Mekah tidak menguntungkan bagi kaum muslimin, karena makin besarnya tekanan kaum Quraisy serta efisiennya boikot mereka terhadap kaum muslimin. Inilah faktor pendorong (push factor) bagi terjadinya hijrah. Ketiga, turunnya wahyu untuk melakukan hijrah dan ini adalah factor yang paling menentukan (determinant factor) (Su'ud, 2003: 34).

Dalam melakukan hijrah kaum muslimin ada yang berangkat dalam bentuk rombongan dan ada pula yang berangkat secara perorangan, hingga Mekah hampir kosong dari orang-orang yang memeluk agama Islam (al- Ghazali, 199). Demikianlah secara berangsur-angsur kaum muslim melakukan hijrah ke Madinah sehingga tidak ada yang tertinggal di makah kecuali Rasulullah Saw., Abu Bakar ra., Ali ra., orang-orang yang di tahan, orang-orang sakit dan orang-orang yang tidak mampu keluar (Ramadhan, 237). Setelah orang-orang musyrik mengetahui para sahabat rasulullaah saw. Meninggalkan Mekah sulit digambarkan bagaimana kekhuwatiran dankegundahan yang menghantui mereka. Oleh karna itu mereka berusaha mencari sarana yang paling efektif untuk menyingkirkan bahaya ini, yang sumbernya Uadalah pembawa bendera dakwah Islam. Yang tidak lain adalah Muhammad. Akhirnya mereka berkumpul di Darun Nadwah untuk mengambil keputusan tegas mengenai persoalan itu. Dan mereka pun mensetujui pendapat yang dikemukakan Abu Jahal sebagai berikut: "menurutku, setiap suku harus memilih para pemudannya yang kuat dan perkasa. Mereka semua harus membunuh Muhammad secara serentak. Dengan cara ini Bani Hasyim tidak akan mampu membalas dendam, karena semua suku ikut terlibat. Jika Bani Hasyim meminta ganti rugi, kita akan sanggup membayarnya barsama-sama." Malam itu, Nabi menrima wahyu untuk berhijrah. Tentang taktik pelaksanaan hijrah, dikatakan pada Ali agar dia mau tidur di tempat tidur 
nabi untuk mengecoh orang-orang Quraisy yang memburunya. Mereka merasa yakin akan dapat membunuh nabi. Ketika menyaksikan Nabi Muhammad masih tergolek di tempat tidur, sama sekali mereka tidak mengira bahwa yangberbaring itu Ali bin Abi Thalib. Nabi sendiri bersama Abu Bakar diam-diam telah menyelinap keluar pada suatu saat dimalam hari yang hening.

Malam itu juga Nabi beserta Abu Bakar bergegas ke gua Tsur. Disana mereka bersembunyi selama tiga hari tiga malam tanpa di ketahui musuh. Namun akhirnya, kepergian itupun di ketahui dan mereka menyusul ke gua Tsur. Aneh sekali, konon para pemburu Nabi meragukan dugaan semula bahwa di dalam gua itu bersembunyi Nabi Muhammad, karna dua alasan. Pertama, pintu gua penuh dengan jaring laba-laba yang sama sekali tidak terusik dan tidak rusak. Kedua, karena di pintu gua itu pula terdapat sarang tempat sejoli merpati sedang mengerami telur mereka. Pada hari ke empat rombongan kecil itu menuju Yatrsib dengan menyisir pantai laut merah dan mereka sampai di Quba' 5 km arah selatan Yatsrib, tepat pada hari senin, 12 Rabiul Awal.

\section{Kenapa Nabi Memilih Madinah}

Jauh sebelum peristiwa hijrah dilakukan oleh nabi dan para sahabatnya, sejumlah pemimpin kabilah di Madinah dari Bani Khuraedhoh dan BaniKhujroj pernah mendatangi Rasul. Mereka menyatakan bahwa masyarakat Madinah sanggup melindungi keselamatan pribadi Rasul maupun para pengikut Islam. Karena itu, mereka menghendaki pemeluk Islam pindah memulai hidup baru di Madinah. Menanggapi tawaran itu, Rasul mendorong para pengikutnya untuk pindah ke Madinah. 4 Dari keterangan ini dapat di ambil pengertian bahwa salah satu faktor hijrahnya nabi ke Madinah adalah adalah adanya tawaran dari orang-orang Islam di madinah agar nabi dan para sahabatnya menetap di kota tersebut, yang selanjutnya dapat dianggap sebagai pusat penyiaran Islam di Arab. Faktor lain yang mendorong hijrahnyanabi ke Madinah adalah adanya perintah berhijrah ke kota itu. AlBukhori meriwayatkan dari Aisyah, dia berkata, "Rasulullah saw bersabda kepada orangorang muslim, sesungguhnya telah diperlihatkan kepadaku tempat tujuan hijrah kalian, yang memiliki kebun kurma yang terletak diantara dua daratan yang subur".

\section{Perkembangan Madinah setelah Nabi Muhammad SAW Hijrah}

Dalam rangka memperkokoh masyarakat dan negara baru, nabi segera meletakkan dasar-dasar kehidupan bermasyarakat, yaitu: pertama, mendirikan masjid. Setelah agama Islam datang,rasulullah bermaksud hendak mempersatukan suku-suku bangsa ini, dengan jalan menyediakan suatu tempat pertemuan. Ditempat ini semua penduduk dapat bertemu untuk mengerjakan ibadah dan pekerjaan-pekerjaan atau upacara-upacara lain. Maka Nabi mendirikan masjid, dan di beri nama "Baitullah". Di masjid ini kaum muslimin dapat bertemu mengerjakan ibadah, belajar mengadili perkara-perkara, jual-beli, upacara-upacara lain.Kemudian ternyata bahwa banyak terjadi8 hiruk-pikuk yang mengganggu orang-orang yang sedang sembah yang. Maka dibuatkanlah suatu tempat yang khas untuk sembahyang, dan satu lagi khas untuk jual beli, tempat yang dibuat khas untuk "masjid". Masjid ini memegang peranan besar untuk mempersatukan kaum muslimin dan mempertalikan jiwa mereka.Tujuan Rasulullah mendirikan masjid adalah untuk 
mempersatukan umat islam dalam satu majlis, sehingga majlis ini umat islam bias bersamasama melaksanakan shalat jama'ah secara teratur, mengadili perkara- perkara dan berusyawarah. Masjid ini memegang peranan penting untuk mempersatukan kaum muslimin dan memper erat tali ukhuwah Islamiyah.

Masjid itu merupakan sebuah ruangan terbuka yang luas, keempat temboknya dibuat dari batu batadan tanah. Atapnya sebagian terdiri dari daun kurma dan sebagian lagi dibiarkan terbuka, dengan salah satu bagian lagi digunakan tempat orang-orang fakir miskin yang tidak punya tempat tinggal. Tidak ada penerangan dalam masjid itu pada malam hari. Hanya pada waktu shalat Isya diadakan penerangan dengan membakar jerami. Yang demikian ini berjalan selama sembilan bulan. Sesudah itu kemudian baru mempergunakan lampu-lampu yang dipasang pada batang-batang kurma yang dijadikan penopang atas itu. Sebenarnyatempat-tempat tinggal Nabi sendiri tidak lebih mewah keadaannya daripada masjid, meskipun memang sudah sepatutnya lebih tertutup. Kedua, mempersatukan dan Mempersaudarakan antara Kaum Anshar dan Muhajirin.

Rasulullahtelahmemepertalikankeluarga-keluarga Islam yang terdiri dari Muhajirin dan Anshar. Masing-masing keluarga mempunyai pertalian yang erat dengan keluarga-keluarga yang banyak, karenaikatanpersaudaraan yang diadakan rasulullah. Persaudaraan ini pada permulaannya mempunyai kekuatan dan akibat sebagai yang dipunyai oleh persaudaraan nasab, termasuk diantaranya hal pustaka,hal tolong-menolong dan lain-lain. Dengan mengadakan persaudaraan seperti ini rasulullah telah menciptakan suatu persatuan yang berdasarkan agama pengganti persaudaraan yang berdasar kesukaran seperti yang banyak terjadi sebelunya. Menjalin hubungan persahabatan antara kaum muslim dengan yang tidak beragama Islam Nabi Muhammad SAW hendak menciptakan toleransi antar golongan yang ada di Madinah, oleh karena itu Nabi membantu perjanjian antara kaum muslimin dengan non muslimin. Kebebasan Beragama Bagi Seluruh Penduduk Madinah Ia melihat adanya suku-suku yang saling bertentangan dalam kota ini, yang di Mekah tidak dikenal. Tapi juga ia melihat kabilah-kabilah dan suku-suku itu semua merindukannya adanya suatu kehidupan yang damai dan tentram, jauh dari segala pertentangan dan kebencian, yang pada masa lampau telah memecah- belah mereka. Tujuan Rasulullah yang pertama dan yang terakhir, ia meneruskan risalah, yang penyampaiannya telah dipercayakan Allah kepadanya, dengan mengajak dan memberikan peringatan. Akan tetapi, oleh penduduk Mekah sendiri, dengan cara kekerasan risalah ini dilawan mati-matian, sejak awal kerasulannya sampai pada waktu hijrah.

Tujuan ialah memberikan ketenangan jiwa bagi mereka yang menganut ajarannya dengan jaminan kebebasan bagi mereka dalam menganut kepercayaan agama masingmasing. Baik bagi seorang Muslimin, seorang Yahudi, atau seorang Kristen masingmasing mempunyai kebebasan yang sama dalam menganut kepercayaan, kebebasan yang sama menyatakan pendapat dan kebebasan yang sama pula dalam menjalankan propanganda agama. Dalam langkahnya Rasulullah mengadakan Ikrar Aqaba ini terjadi ketika dua belas penduduk Yathrib yang bertemu dengan Nabi di 'Aqaba. Ditempat inilah mereka menyatakan ikrar atau janji kepada Nabi (yang kemudian dikenal dengan nama) Ikrar 'Aqaba pertama. Mereka berikrar kepadanya untuk tidak menyekutukan Tuhan, tidak mencuri, tidak berzina, tidak membunuh anak-anak, tidak mengumpat dan menfitnah, baik 
di depannya atau di belakang. Rasulullah berpedoman pada ayat: "Diijinkan (berperang) kepada mereka yang diperangi, karena mereka dianiaya, dan sesungguhnya Allah Maha Kuasa menolong mereka." (Al-Anfal :39); dan :'Dan perangilah mereka supaya jangan ada lagi fitnah, dan agama seluruhnya untuk Allah." (Al-Baqarah : 193).

Pertimbangan Nabi Muhammad Saw adalah menjamin kebebasan beragama dan menyatakan pendapat. Hanya untuk mempertahankan itulah perang dibenarkan, dan hanya untuk itu pula dibenarkan menangkis pihak agresor. Muhammad Mempersaudarakan Kaum Muhajirin Dengan Anshar. Untuk mencapai maksud ini diajaklah kaum Muslimin supaya masing-masing menjadi saudara, demi Allah. Dia sendiri bersaudara dengan Ali bin Abi Talib, Hamzah pamannya bersaudara dengan Zaid bekas budaknya. Abu Bakr bersaudara dengan Kharija bin Zaid. Umar Ibnul Khattab, bersaudara dengan 'Itban bin Malik al- Khazraji. Demikian juga setiap orang dari kalangan Muhajirin yang sekarang sudah banyak jumlahnya di Yathrib, sesudah mereka yang tadinya masing tinggal di Mekah menyusul ke Madinah setelah Rasul hijrah, dipersaudarakan pula dengan setiap orang dari pihak Anshar, yang oleh Rasul lalu dijadikan hukum saudara sedarah senasib dengan persaudaraan demikian ini persaudaraan kaum Muslimin bertambah kukuh adanya.

Kaum Anshar telah meninggalkan Mekah, dan bersama itu mereka tinggalkan pula segala yang mereka miliki, harta benda dan semua kekayaan. Sebagian besar ketika mereka memasuki Madinah sudah hampir tidak ada lagi yang akan dimakan, di samping mereka memang bukan orang berada dan berkecukupan selain Usman bin 'Affan. Sedangkan yang lain sedikit sekali yang dapat membawa sesuatu yang berguna dari Mekah. Pada suatu hari Hamzah paman Rasul pergi mendatanginya dengan permintaan kalau-kalau ada yang dapat di makannya. Abdur-Rahman bin 'Auf yang sudah bersaudara dengan Sa'd bin 'rRabi ketika di Yathrib ia sudah tidak punya apa-apa lagi. Ketika Sa'd menawarkan hartanya akan dibagi dua, Abdur-Rahman menolak. Ia hanya minta ditunjukkan jalan ke pasar. Dan disanalah dia mulai berdagang mentega dan keju. Dalam waktu tidak lama, dengan kecakapannya berdagang ia telah dapat mencapai kekayaan kembali, dan dapat pula memberikan mas-kwain kepada salah seorang wanita di Madinah.

Abu Bakar, Umar, Ali bin Talib dan lain-lain mereka terjun ke dalam pertanian, menggarap tanah milik orang-orang Anshar bersama-sama pemiliknya.Di samping itu ada ada lagi segolongan orang-orang yang Arab yang datang ke Madinah dan menyatakan masuk Islam, dalam keadaan miskin dan serba kekurangan sampai-sampai ada diantara mereka yang tidak punya tempat tinggal. Bagi mereka ini oleh Muhammad disediakan tempat di selasar masjid yaitu shuffa bagian masjid yang beratap, sebagai tempat tinggal mereka. Antara kaum Muhajirin dan Anshar dengan orang-orang Yahudi, Muhammad membuat suatu perjanjian tertulis yang berisi pengakuan atas agama merkea dan harta benda mereka, dengan syarat-syarat timbal balik. Dokumen politik yang telah diletakkan Muhammad sejak seribu tiga ratus lima puluh tahun yang lalu danyan telah menetapkan adanya kebebesan beragama, kebebasan menyatakan pendapat, tentang kesalamatan harta benda dan larangan orang melakukan kejahatan. Ia telah membuka pintu baru dalam kehidupan politik dan peradaban dunia pada masa itu. Dunia, yang selama ini hanya menjadi permainan tangan tirani, dikuasai oleh kekejaman dan kehancuran semata. Apabila dalam penandatanganan dokumen ini orang-orang Yahudi Banu Quraiza, Banu'n Nadzir dan Banu Qainuqa tidak ikut serta, namun tidak lama selang sesudah itu mereka pun 
mengadakan perjanjian yang serupa dengan Nabi Muhammad Saw. Seluruh kota Madinah dan sekitarnya telah benar-benar jadi terhormat bagi seluruh penduduk. Mereka berkewajiban mempertahankan kota ini dan mengusir setiap serangan yang datang dari luar. Mereka harus bekerja sama antara sesama mereka guna menghormati segala hak dan segala macam kebebasan yang sudah disetujui bersama dalam dokumen ini.

\section{Kesimpulan}

Setelah turun ayat 94, surah Al-Hijr, Nabi Muhammad Saw memulai berdakwah secara terang-terangan, namun dakwah yang dilakukan beliau tidak mudah karena mendapat tantangan dari kaum kafir Quraisy. Perjanjian Aqobah menjadi dasar hijrah yang dilakukan oleh Nabi Muhammad Saw. Mendengar rencana hijrah tersebut,kaum Quraisy merencakan pembunuhan terhadap Nabi Muhammad memerintahkan umat Islam

Berhijrah ke Yatsrib terlebih dulu dan sebagian sahabat beserta Nabi Muhammad Saw melancarkan sebuah strategi yang melibatkan banyak pihak agar hijrah yang dilakukan berhasil dan dapat menggagalkan rencana pembunuhan yang dilakukan elit Quraisy.

Dalam perjalanan ke Yasrib nabi di temani oleh Abu Bakar. Ketika tiba di Quba, sebuah desa yang jaraknya sekitar lima kilo meter dari yasrib,nabi muhammad beristirahat beberapa hari lamanya. Dia menginap di Rumah Kulsum bin Hindun.Tak lama kemudian ali menggabungkan diri dengan nabi, setelah menyelsaikan segala urusan di Makkah. Sementara itu, penduduk yasrib menunggu-nunggu kedatangannya. Waktu yang mereka tunggu-tunggu itu tiba. Nabi memasuki yasrib dan penduduk kota ini mengelu- elukan kedatangan beli udengan penuh kegembiraan.

Sebagai penghormatan terhadap nabi, nama kota Yasrib diubah menjadi Madinatun Nabi (Kota Nabi) atou sering pula di sebut Madinatul munawarah (kota yang bercahaya), karena dari sanalah sinar islam memancar keseluruh dunia. Dalam istilah sehari-hari,kota ini cukup di sebut madinah saja. Dalam rangka memperkokoh masyarakat dan negara baru, nabi segera meletakkan dasar-dasar kehidupan bermasyarakat, yaitu: (1) mendirikan masjid; (2) mempersatukan dan mempersaudarakan antara kaum Anshar dan Muhajirin; (3) menjalin hubungan persahabatan antara kaum muslim dengan yang tidak beragama Islam; dan (4) meletakkan dasar-dasar politik, ekonomi, dan sosial untuk masyarakat baru.

\section{DAFTAR PUSTAKA}

Al- Buthy, Muhammad Sa'id Ramadhan. Terjemahan, Sirah Nabawiyyah. Bairut;Darul Fikri. Cet,6. 1977.

Al-Ghazali, Muhammad. Sejarah Perjalanan Hidup Muhammad. Yogyakarta; Mitra Pustaka. 2006

Badri yatim, sejarah peradaban islam, jakarta: PT. RajaGrafindo Persada, 2003

Faud Hashem, Sirah Muhammad Rasulullah: Suatu penafsiran Baru, Bandung:Mizan, 1996

Muhammad husain haekal, sjarah hidup muhammad, Jakarta: PT.

Tinta mas Indonesia 1990

Su'ud Abu. Islamologi Sejarah, Ajaran, dan Peranannya dalam Peradaban Umat Islam.

Jakarta; Rineka Cipta.2003.

Suhardi, Kathur, Terjemahan Sirah Nabawiyah, Syekh Shafiyurrahman Al-mubarakfuri, Pustaka Al-Kautsar, Jakarta Timur; 2003 